\title{
Multi-Objective Optimization of Acoustical Properties of PU-Bamboo-Chips Foam Composites
}

\author{
Yang JIANG, Shuming CHEN, Dengfeng WANG, Jing CHEN \\ State Key Laboratory of Automotive Simulation and Control \\ Jilin University \\ No. 5988 Renmin Street, Changchun, 130022, China; e-mail: smchen@jlu.edu.cn \\ (received May 11, 2016; accepted August 7, 2017)
}

\begin{abstract}
In this study, an effective optimization approach was proposed to improve acoustical behaviors of PU foams. The important parameters of PU foams: content of water, silicone oil and catalyst A1 were chosen and their effects on sound absorption coefficient and transmission loss of PU foams were studied by using Taguchi methods. In addition, bamboo chips were incorporated into PU foams as fillers to improve the acoustical properties of PU foams. Four controlled factors: the content of water, silicone oil, catalyst A1 and bamboo chips with three levels for each factor were chosen and Taguchi method based on orthogonal array $\mathrm{L}_{9}\left(3^{4}\right)$ was employed to conduct the experiments. Based on the results of Taguchi's orthogonal array $\mathrm{L}_{9}\left(3^{4}\right)$, signal-to noise $(\mathrm{S} / \mathrm{N})$ analysis was used and developed to determine an optimal formulation of PU-bamboo-chips foam composites.
\end{abstract}

Keywords: vehicle sound package; sound absorption coefficient; transmission loss; Taguchi method.

\section{Introduction}

Noise pollution has aroused increased public concern due to the rapid developments of modern industries and transportations. Especially, the car has been major source of environmental noise pollution. The vehicle noise not only pollutes the surrounding environment, but also leads to deterioration of the vehicle internal environment and further affects vehicle ride comfort. Therefore, the improved acoustical performances in the interior of an automobile that exhibit good absorption and transmission characteristics are strongly desired. Flexible polyurethane foams (PU foams) with high porosity have been extensively used as noise control materials in the automotive industry due to effective sound absorption, light weight, excellent viscoelasticity and acoustic absorption properties (Gayathri, Vasanthakumari, 2014; GWon et al, 2016). They are used in interior components such as seats, inner dash mats, carpet assemblies, fender insulations and other acoustic trim parts (Gayathri et al., 2013; Yin et al., 2011).

PU foams can be generally obtained from the simultaneous reaction of polyisocyanates with polyols, water, catalysts and other additives. The cell size as well as interconnectivity can play a crucial role in governing the acoustic behaviors of PU foams since the acous- tic wave penetration was controlled inside the porous frame and thus dissipates the acoustic energy into heat (LEE et al., 2012). The cell structure characteristics of flexible polyurethane foam are directly affected by various main ingredients used in the foam formulations such as the blowing agent, catalysts and surfactants. Additionally, the cellular structure can be also controlled by varying the foam mix ratio, the weight proportion of isocyanates and polyols, further influencing acoustic performances (GWON et al., 2016). Two main chemical reactions happen during polymerization: gelling reaction and blowing reaction. The former is to produce urethane bonds between isocyanates and polyols, the latter is to drive the foam expansion by generating carbon dioxide $\left(\mathrm{CO}_{2}\right)$ due to the reaction of the isocyanate with water. $\mathrm{PU}$ foams with a porous cellular construction are formed under these two reactions, which are balanced by the addition of catalysts and surfactants.

Recently, the improvement of sound absorption efficiency can be accomplished through a number of methods such as the modification of the cellular structures (YIN et al., 2011), the addition of various kinds of additives, various nano- and micro-particles in PU foams (GAYAThri et al., 2014; LeE et al., 2012; Andersson et al., 2010; ZHANG et al., 2012; LI et al., 2015). PU foams incorporated with polyacryloni- 
trile (PAN), polyurethane nanofibers, multiwall carbon nanotubes (MWNTs) and nanoclay were studied by Hossein et al. to enhance sound absorption behaviors (BAHRAMBEYGi et al., 2013). It turned out that both nanoparticles gave rise to considerable improvement in sound absorption of PU foams and MWNTs were observed to achieve the most satisfied results. Polymer microparticles with different structures, sizes scales and size distributions were enclosed in PU foams by ZHOU et al. (2006) and the sound absorption characteristics of $\mathrm{PU}$ composites were greatly improved by incorporating the polymer microparticles. Flexible PU foams filled with three different fillers namely nano silica, crumb rubber and nano clay were prepared to study their effects on sound absorption at low frequency range by Gayathri et al., and maximum sound absorption coefficient of $80 \%$ was obtained at $1.4 \%$ weight concentration of all the three fillers (GAYATHRI et al., 2013). Besides, numerous studies have also been carried out to enhance sound absorption properties by adding natural fibers or agricultural byproducts into PU foams. PU foams loaded with natural tea-leaf fibers and luffa cylindrical were prepared to improve the sound absorption property by EKICI et al. (2012), and it turned out that luffa cylindrical as a filler material significantly improved sound absorption properties of soft foams at all frequency ranges. PU composites with rice hull were fabricated to analyze their sound absorption capacity by WANG et al. (2013) and they exhibited an obvious improvement in sound absorption and sound damping properties. In this paper, bamboo fibers were added into PU foams to investigate the effects of bamboo fibers on the acoustic properties since the bamboo fibers have already show potential ability in improving sound absorption and mechanical properties (HUdA et al., 2012). At the same time, different ingredients of PU foams such as two catalysts, water and bamboo fibers were chosen as variables to optimize the acoustic properties of PU foams and to obtain an optimum formulation of PU-bamboo-fiber foams with improved acoustic properties. Sound absorption and sound transmission loss were chosen as the objectives to quantify the acoustic performances.

The Taguchi method is a powerful tool for designing and analyzing the experiments to obtain high quality products at low cost and minimum number of experiments. It provides a simple, efficient and systematic approach to estimate the effects of several variables separately, simultaneously or as combinations (Low et al., 2011; AdELI et al., 2011). The Taguchi method based on orthogonal arrays (OA) has been applied to perform the present experiments and the sound absorption and transmission loss of PU-bamboochips foam composites were studied.

The outline of the paper is organized as follows. In Sec. 2, the experimental materials and fabrication method of PU foams are specified, followed by the acoustic testing of PU foams. In Sec. 3, multi-objective optimizations are performed to simultaneously maximize the sound absorption and transmission loss by using $\mathrm{S} / \mathrm{N}$ ratio. Finally, the conclusion is drawn in Sec. 4.

\section{Experimental materials and methods}

\subsection{Raw materials}

Polyether polyol $330 \mathrm{~N}$ (OH-value: $33-36 \mathrm{mg}$ $\mathrm{KOH} / \mathrm{g}$ ), polyether polyol 3630 (OH-value: $33-37 \mathrm{mg}$ $\mathrm{KOH} / \mathrm{g}$ ) were chosen together with modified MDI (diphenylmethane 4,4-diisocyanate). Catalysts A1 (mixture of $70 \%$ bis (2, dimethylamino ethyl) ether and 30\% dipropylene glycol) and catalysts A 33 (solution of $33 \%$ triethylenediameine) were both chosen as the amine catalysts. The surfactants was silicone oil Tri-ethanolamine (TEA), deionized water and HCFC$141 \mathrm{~b}$ widely used in the PU foams industry were both chosen for blowing agents. The materials mentioned above were supplied by Juyi Chemical Corporation Ltd., Guangdong. Table 1 shows the materials used for preparation of PU foams.

Table 1. Neat foam formulation.

\begin{tabular}{|l|c|}
\hline \multicolumn{1}{|c|}{ Materials } & \multicolumn{1}{c|}{$\begin{array}{c}\text { Content of each } \\
\text { material }\end{array}$} \\
\hline Polyols (330N, 3630) & $330 \mathrm{~N}=60 ; 3630=40$ \\
\hline Isocyanate (Modified MDI) & 30 \\
\hline Amine catalyst A33 & 1.0 \\
\hline Catalyst (TEA) & 1.0 \\
\hline Blowing agent (141b) & 5.0 \\
\hline Surfactant (Silicone oil) & $1.2-1.8$ \\
\hline Blowing agent (Deionized water) & $3.8-4.6$ \\
\hline Amine catalyst A1 & $0.08-0.12$ \\
\hline
\end{tabular}

The bamboo leaves were purchased from Sichuan, China. Prior to the synthesis of PU-bamboo foam composites, the bamboo leaves were already dried under vacuum at room temperature. The bamboo leaves were ground into smaller chips with a mill. The length of bamboo chips employed in the PU foam composites was $1-2 \mathrm{~mm}$. Figure 1 shows the photographs of the bamboo chips.

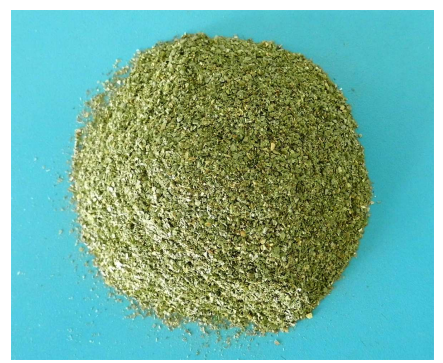

Fig. 1. Bamboo chips prepared for PU foam composites. 


\subsection{Synthesis of PU-bamboo-chips foam composites}

The PU foams with varied content of bamboo chips were prepared. Firstly, deionized water, TEA, and $141 \mathrm{~b}$ were mixed with polyols, catalyst A1, catalyst A33 and surfactant at $2000 \mathrm{rpm}$ for $10 \mathrm{~min}$ by using the mechanical stirrer. Subsequently, bamboo chips were added to the mixture and mixed for 5 minutes, afterward, modified MDI was added to the bamboo chips/polyols mixture at last step. Finally, the whole components were stirred again thoroughly with the mechanical stirrer for 15 second and the mixture was then poured rapidly into the stainless steel mold. The size of the mold was $60 \mathrm{~mm}$ in height, $150 \mathrm{~mm}$ both in width and length. The foams were put into a drying oven for $24 \mathrm{~h}$ to be cured and the temperature was set at $50^{\circ} \mathrm{C}$. The foams were removed from the mold and then aged for $24 \mathrm{~h}$ at room temperature before being cut for analysis.

\subsection{Experimental parameters and design}

In this case, the novel PU-bamboo-chips foam composites were incorporated by bamboo chips in order to obtain an acoustic material with improved sound absorption and sound insulation properties. The effects of process parameters in the formulation of PU-bamboochips foam composites and the optimum combination for acoustic properties of PU-bamboo-chips foam composites were studied by using Taguchi approach. The experiments were conducted with four controllable 3levels factors and two objectives. Table 2 shows four controlled factors, i.e., the content of water (i.e., A), the content of silicone oil (i.e., B), the content of catalyst A1 (i.e., C) and the content of bamboo chips (i.e., D) with three levels for each factor. The orthogonal arrays $\mathrm{L}_{9}\left(3^{4}\right)$ was chosen and then 9 experimental runs were carried out based on the design matrix shown in Table 3. In engineering, noise reduction coefficient (NRC) is commonly used as an evaluation parameter to characterize sound absorbing materials. NRC is defined as arithmetic mean of the absorption coefficient $\alpha$ at frequencies of 250, 500, 1000 and $2000 \mathrm{~Hz}$, which is defined in the following equation,

$$
\mathrm{NRC}=\frac{\alpha_{250}+\alpha_{500}+\alpha_{1000}+\alpha_{2000}}{4} .
$$

Table 2. Description of factors and their levels for Taguchi experimental design.

\begin{tabular}{|l|c|c|c|c|}
\hline \multirow{2}{*}{ Variables } & \multirow{2}{*}{ Parameter code } & \multicolumn{3}{|c|}{ Level } \\
\cline { 3 - 5 } & & -1 & 0 & 1 \\
\hline Water & $\mathrm{A}$ & 3.8 & 4.2 & 4.6 \\
\hline Silicone oil & $\mathrm{B}$ & 1.2 & 1.5 & 1.8 \\
\hline Catalyst A1 & $\mathrm{C}$ & 0.08 & 0.10 & 0.12 \\
\hline Bamboo chips & $\mathrm{D}$ & 2 & 4 & 6 \\
\hline
\end{tabular}

Table 3. Orthogonal array $\mathrm{L}_{9}\left(3^{4}\right)$ of experimental design.

\begin{tabular}{|l|c|c|c|c|}
\hline \multirow{2}{*}{ Run } & \multicolumn{4}{|c|}{ Factor } \\
\cline { 2 - 5 } & $\mathrm{A}$ & $\mathrm{B}$ & $\mathrm{C}$ & $\mathrm{D}$ \\
\hline 1 & 3.8 & 1.2 & 0.08 & 2 \\
\hline 2 & 3.8 & 1.5 & 0.10 & 4 \\
\hline 3 & 3.8 & 1.8 & 0.12 & 6 \\
\hline 4 & 4.2 & 1.2 & 0.10 & 6 \\
\hline 5 & 4.2 & 1.5 & 0.12 & 2 \\
\hline 6 & 4.2 & 1.8 & 0.08 & 4 \\
\hline 7 & 4.6 & 1.2 & 0.12 & 4 \\
\hline 8 & 4.6 & 1.5 & 0.08 & 6 \\
\hline 9 & 4.6 & 1.8 & 0.10 & 2 \\
\hline
\end{tabular}

Similarly, ATL (the average transmission loss) is arithmetic average of the transmission loss derived here at the 17 1/3 octave band between 100 and $4000 \mathrm{~Hz}$ at frequencies of $100,125, \ldots, 3150,4000 \mathrm{~Hz}$, which is defined in the following equation,

$$
\mathrm{ATL}=\frac{t l_{100}+t l_{125}+\cdots+t l_{3150}+t l_{4000}}{17} .
$$

Thereby, NRC and ATL of PU foams were both selected as target objectives, the higher NRC the better sound absorbing and sound insulation abilities. Upon completion of the nine experimental runs, the corresponding responses (sound absorption coefficient and transmission loss) were tested by acoustical property measurements.

\subsection{Acoustic property measurement}

The tests for sound absorption coefficient and transmission loss were performed by using SCS90AT acoustic material properties measurement system. The measurement system comprises of an impedance tube, four microphones, loudspeaker and digital frequency analyzer. The sound absorption coefficient was obtained by using a two-microphone impedance tube based on transfer function method in accordance to ISO 10534-2:1998 standard (ISO, 1998) and ASTM E1050-98 international standards (ASTM, 1998). The normal incidence sound transmission loss of acoustic materials was determined by using a four-microphone impedance tube according to ASTM E 2611-09 international standards (ASTM, 2009). Cylindrical samples with a diameter of $100 \mathrm{~mm}$ were used for the low-frequency range $(100-1900 \mathrm{~Hz})$ and samples with $28 \mathrm{~mm}$ diameter were used for the high-frequency range $(1000-6300 \mathrm{~Hz})$. All the samples had a thickness of $30 \mathrm{~mm}$. Figure 2 shows the sample foams used for acoustic test. Figure 3 presents the schematic for sound absorption and transmission loss test. Each of the tests was repeated with at least four times to obtain consistent and representative results. 


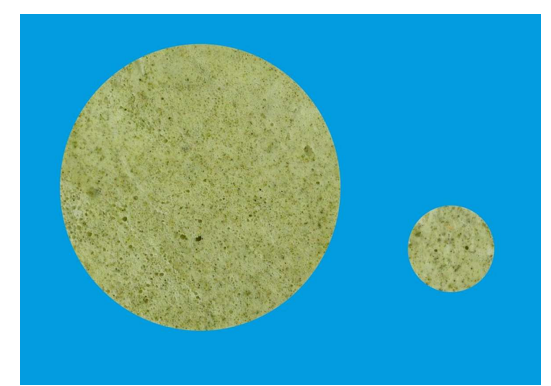

Fig. 2. Photographs of PU foam composites samples for low- and high-frequency acoustic test.

a)

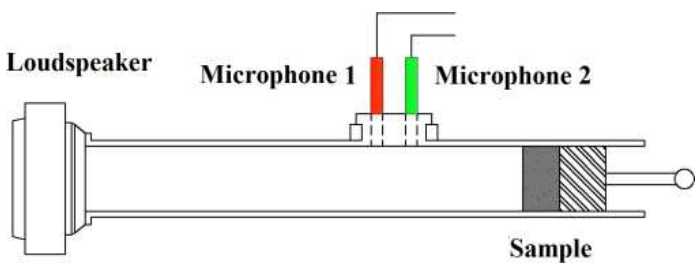

b)

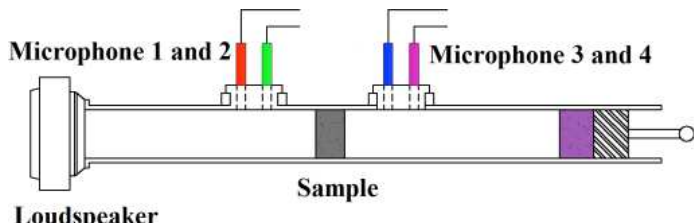

Fig. 3. Schematic of the experimental setup for: a) absorption coefficient testing and b) transmission loss testing.

\section{Results and discussion}

\subsection{Signal-to-noise $(S / N)$ ratio}

Signal-to-noise ratio is used to measure the performance characteristic in Taguchi method, and then the experimental results are transformed to $\mathrm{S} / \mathrm{N}$ ratio. Generally, there are three types of performance characteristic in the analysis of the $\mathrm{S} / \mathrm{N}$ ratio, which are the lower the better, the higher the better and the nominal the better, respectively.

1) the lower the better:

$$
\eta=-10 \times \log \left(\frac{1}{n} \sum_{i=1}^{n} y_{i}^{2}\right),
$$

2) the higher the better:

$$
\eta=-10 \times \log \left(\frac{1}{n} \sum_{i=1}^{n} \frac{1}{y_{i}^{2}}\right),
$$

3) the nominal the better:

$$
\eta=-10 \times \log \left(\frac{1}{n s} \sum_{i=1}^{n} y_{i}^{2}\right),
$$

where $\eta$ represents the $\mathrm{S} / \mathrm{N}$ ratio, $y_{i}$ represents a quality measurement, $n$ represents the total number of the tests, $s$ represents the standard deviation.
The quality characteristics in this study are NRC and ATL, for both of NRC and ATL, the higher NRC and ATL are preferred. Therefore, the quality characteristics of the NRC and ATL are the higher the better.

\subsection{Analysis of the $S / N$ ratio}

Based on the results of acoustic performances, the $\mathrm{S} / \mathrm{N}$ ratio was used to determine the important effect of four parameters. The experiments results were further transferred to $\mathrm{S} / \mathrm{N}$ ratio. According to the quality characteristic of the results, a higher $\mathrm{S} / \mathrm{N}$ ratio corresponds to the better quality. The optimal level of four factors is the level with the highest $\mathrm{S} / \mathrm{N}$ ratio. Table 4 and Table 5 shows the experiment results and corresponding $\mathrm{S} / \mathrm{N}$ ratio for $\mathrm{NRC}$ and ATL, respectively.

Table 4. Experimental results of NRC and corresponding $\mathrm{S} / \mathrm{N}$ ratio.

\begin{tabular}{|c|c|c|c|c|c|c|}
\hline \multirow{2}{*}{ Run } & \multicolumn{4}{|c|}{ Factor } & \multicolumn{2}{c|}{ Responses } \\
\cline { 2 - 7 } & $\mathrm{A}$ & $\mathrm{B}$ & $\mathrm{C}$ & $\mathrm{D}$ & NRC & S/N ratio \\
\hline 1 & 3.8 & 1.2 & 0.08 & 2 & 0.573 & -4.837 \\
\hline 2 & 3.8 & 1.5 & 0.10 & 4 & 0.529 & -5.531 \\
\hline 3 & 3.8 & 1.8 & 0.12 & 6 & 0.537 & -5.401 \\
\hline 4 & 4.2 & 1.2 & 0.10 & 6 & 0.572 & -4.852 \\
\hline 5 & 4.2 & 1.5 & 0.12 & 2 & 0.523 & -5.630 \\
\hline 6 & 4.2 & 1.8 & 0.08 & 4 & 0.539 & -5.368 \\
\hline 7 & 4.6 & 1.2 & 0.12 & 4 & 0.542 & -5.320 \\
\hline 8 & 4.6 & 1.5 & 0.08 & 6 & 0.593 & -4.539 \\
\hline 9 & 4.6 & 1.8 & 0.10 & 2 & 0.542 & -5.320 \\
\hline
\end{tabular}

Table 5. Experimental results of ATL and corresponding $\mathrm{S} / \mathrm{N}$ ratio.

\begin{tabular}{|c|c|c|c|c|c|c|}
\hline \multirow{2}{*}{ Run } & \multicolumn{4}{|c|}{ Factor } & \multicolumn{2}{c|}{ Responses } \\
\cline { 2 - 7 } & $\mathrm{A}$ & $\mathrm{B}$ & $\mathrm{C}$ & $\mathrm{D}$ & ATL & S/N ratio \\
\hline 1 & 3.8 & 1.2 & 0.08 & 2 & 10.78 & 20.65 \\
\hline 2 & 3.8 & 1.5 & 0.10 & 4 & 12.83 & 22.16 \\
\hline 3 & 3.8 & 1.8 & 0.12 & 6 & 14.22 & 23.06 \\
\hline 4 & 4.2 & 1.2 & 0.10 & 6 & 12.06 & 21.63 \\
\hline 5 & 4.2 & 1.5 & 0.12 & 2 & 13.23 & 22.43 \\
\hline 6 & 4.2 & 1.8 & 0.08 & 4 & 14.11 & 22.99 \\
\hline 7 & 4.6 & 1.2 & 0.12 & 4 & 14.21 & 23.05 \\
\hline 8 & 4.6 & 1.5 & 0.08 & 6 & 13.44 & 22.57 \\
\hline 9 & 4.6 & 1.8 & 0.10 & 2 & 15.35 & 23.72 \\
\hline
\end{tabular}

The S/N ratio for three levels of four factors for NRC and ATL is computed and listed in Table 6 and Table 7 , the larger value of $\mathrm{S} / \mathrm{N}$ ratio corresponds to larger NRC and ATL, which means the best sound absorption and insulation properties. The order in the Table 6 and Table 7 rank the influence of the corresponding factors on the results. 
Table 6. S/N response for NRC.

\begin{tabular}{|c|l|c|c|c|c|c|}
\hline Symbol & Factor & Level 1 & Level 2 & Level 3 & Max-min & Order \\
\hline A & Water & -5.256 & -5.283 & -5.060 & 0.226 & 4 \\
\hline B & Silicone oil & -5.003 & -5.233 & -5.363 & 0.360 & 3 \\
\hline C & Catalyst A1 & -4.915 & -5.234 & -5.450 & 0.535 & 1 \\
\hline D & Bamboo chips & -5.262 & -5.406 & -4.931 & 0.475 & 2 \\
\hline
\end{tabular}

Table 7. S/N response for ATL.

\begin{tabular}{|c|l|c|c|c|c|c|}
\hline Symbol & Factor & Level 1 & Level 2 & Level 3 & Max-min & Order \\
\hline A & Water & 21.96 & 22.35 & 23.11 & 1.150 & 2 \\
\hline B & Silicone oil & 21.78 & 22.39 & 23.26 & 1.480 & 1 \\
\hline C & Catalyst A1 & 22.07 & 22.50 & 22.85 & 0.780 & 3 \\
\hline D & Bamboo chips & 22.27 & 22.73 & 22.42 & 0.460 & 4 \\
\hline
\end{tabular}

The trends of the $\mathrm{S} / \mathrm{N}$ ratios for four factors at their three designated levels affecting the sound absorption and insulation are shown in Fig. 4 and Fig. 5, respectively. It is well known that the higher $\mathrm{S} / \mathrm{N}$ ratio, the better the response for factorial effect. From the Fig. 4, it can be clearly seen that the best combination of four factors to obtain the maximum NRC value for the $\mathrm{S} / \mathrm{N}$ ratio is at level 3 of water content (4.6 water), level 1 of silicone oil content (1.2 silicone oil), level 1 of catalyst A1 ( 0.8 catalyst A1) and level 3 of bamboo chips (6 bamboo chips). It can be also seen that the factor $\mathrm{C}$ (catalyst A1) has the most significant effect on the $\mathrm{NRC}$, followed by factor D (bamboo chips), factor B (silicone oil) and factor A (water). So the optimal com-

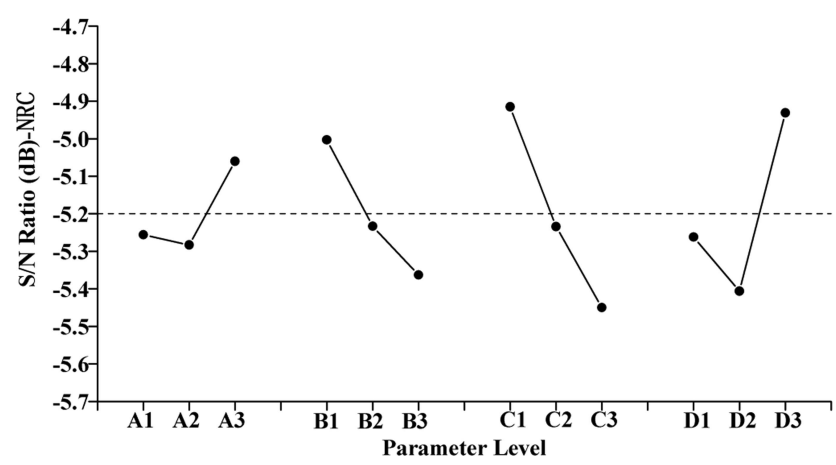

Fig. 4. S/N graph for NRC.

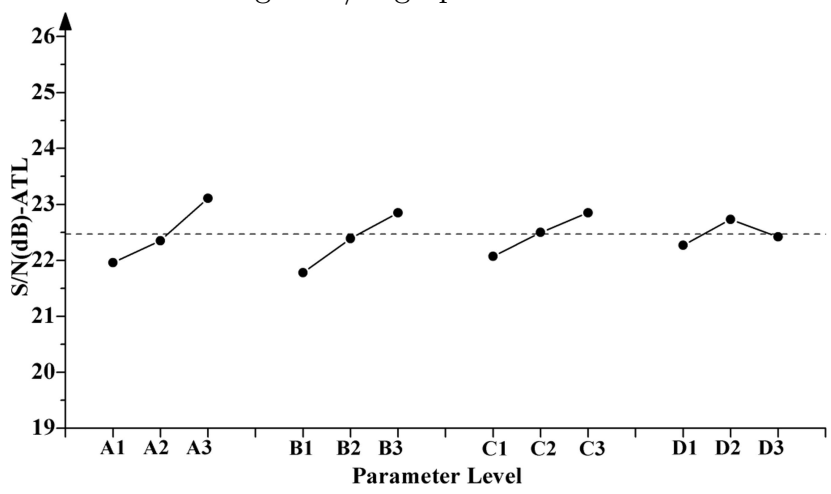

Fig. 5. S/N graph for ATL. bination of parameters can be obtained as $\mathrm{A}_{3} \mathrm{~B}_{1} \mathrm{C}_{1} \mathrm{D}_{3}$ for NRC as shown in Fig. 4.

From the Fig. 5, it can be clearly seen that the best combination of four factors to obtain the maximum ATL value for the $\mathrm{S} / \mathrm{N}$ ratio is at level 3 of water content (4.6 water), level 3 of silicone oil content (1.8 silicone oil), level 3 of catalyst A1 (1.2 catalyst A1) and level 2 of bamboo chips ( 4 bamboo chips). It can be clearly shown that the factor B (silicone oil) has the most significant effect on the ATL, followed by factor A (water), factor $\mathrm{C}$ (catalyst A1) and factor D (bamboo chips). So the optimal combination of parameters can be obtained as $\mathrm{A}_{3} \mathrm{~B}_{3} \mathrm{C}_{3} \mathrm{D}_{2}$ for ATL as shown in Fig. 5 .

The above results revealed that the components of PU-bamboo-chips foam composites significantly affect the sound absorption coefficient and transmission loss of PU-bamboo-chips foam composites. Therefore, suitable amount of deionized water, silicone oil, catalyst A1 and bamboo chips must be determined in order to obtain higher sound absorption coefficient and transmission loss of PU-bamboo-chips foam composites. Based on the $\mathrm{S} / \mathrm{N}$ analysis, the optimal parameter level both for the NRC and ATL were obtained by the overall balance method. Overall balance method takes several steps as follows: firstly, S/N analysis for single target were used to obtain the important orders and optimal level affecting the evaluation indicator; secondly, according to the theoretical knowledge and practical experience, the best combination of optimum levels for each factor was obtained by taking comprehensive comparison and analysis of each indicator into account.

From Table 6 and 7, the content of bamboo chips had the least influence on ATL, however, it played a major role on NRC, thus the optimal content of bamboo chips depended mainly on obtaining the best sound-absorbing properties, the content of bamboo chips was 6 ; as for the content of water had imposed effects both on NRC and ATL, the level 3 of factor A (water) was the best choice to improve the acous- 
tic properties, similarly, the level 3 for factor B and level 1 for factor $\mathrm{C}$ can lead to better results. Thus, from the analysis above, the best combination values for optimizing acoustic properties of $\mathrm{PU}$ foams were $\mathrm{A}_{3} \mathrm{~B}_{3} \mathrm{C}_{1} \mathrm{D}_{3}$ and the optimum parameters are obtained. They are $\mathrm{A}=4.6, \mathrm{~B}=1.8, \mathrm{C}=0.8$, and $\mathrm{D}=6$.

\subsection{Confirmation test}

The optimum combination is not included in the orthogonal array $\mathrm{L}_{9}\left(3^{4}\right)$, so it was necessary to conduct the confirmation test in order to validate the experi- mental results. The experiment was conducted making use of the above obtained optimum parameters. The curves for sound absorption coefficient and transmission loss of the material were shown in Fig. 6 and compared with two of the initial sample points. The results showed the acoustic properties are improved effectively. By calculating the data obtained from the confirmation test, the NRC of the optimal PU foams was 0.645 and the highest sound absorption coefficient was up to 0.999 . The NRC had showed an increased value from 0.593 to 0.645 , improving $8.7 \%$ compared with Run 8 (Table 4), which showed best absorption

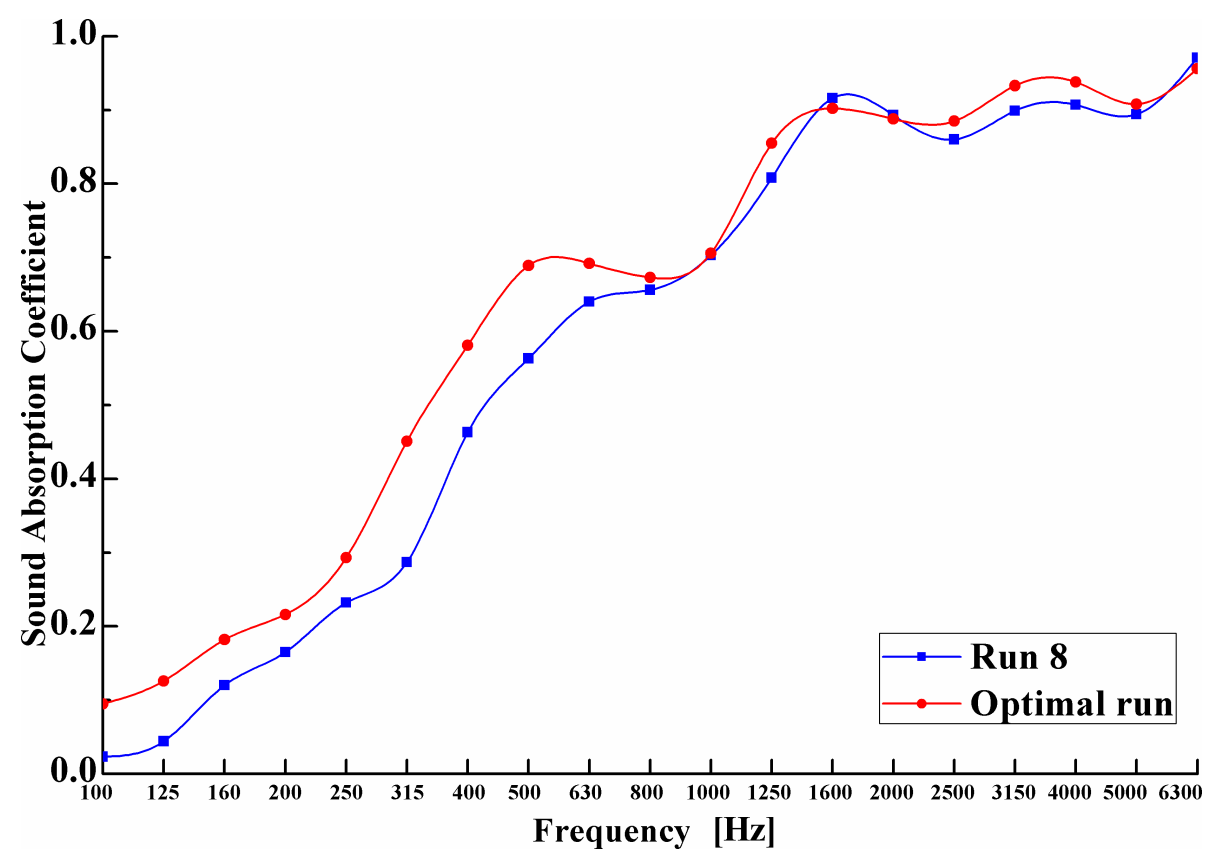

Fig. 6. Curves of sound absorption coefficient for the optimal PU foams.

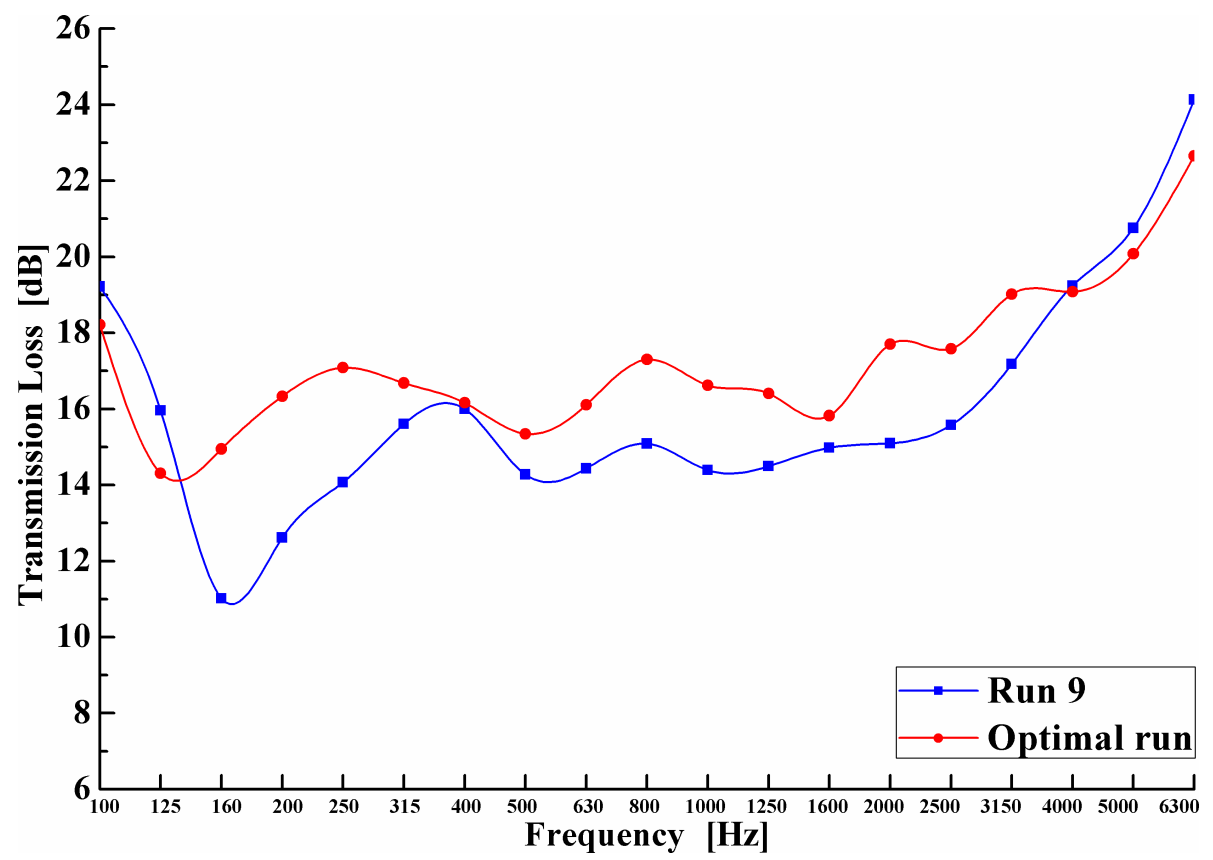

Fig. 7. Curves of transmission loss for the optimal PU foams. 
Table 8. The optimum design of formulation after optimization.

\begin{tabular}{|c|c|c|c|c|c|c|}
\hline Parameters & A & B & C & D & NRC & ATL \\
\hline The optimum design & 4.6 & 1.8 & 0.08 & 6 & 0.645 & 16.75 \\
\hline
\end{tabular}

properties among 9 runs. Similarly, the ATL of the optimal PU foams was 16.75 and had showed an increased value from 15.35 to 16.75 , increasing $9.1 \%$ in contrast with the Run 9 (Table 5).

\section{Conclusions}

This paper proposed an effective optimization approach to improve the acoustical behaviors of PUbamboo-chip foam composites by optimizing the formulation of PU foams. Taguchi method based on the orthogonal array $\mathrm{L}_{9}\left(3^{4}\right)$ was employed to conduct the experiments. Sound absorption coefficient and transmission loss were selected as the objectives. To further achieve the optimum formulation of $\mathrm{PU}$ foams, the multi-objectives optimization in terms of two objectives and four design variables was formulated aiming to simultaneously maximize the sound absorption and sound transmission loss. Signal-to noise (S/N) analysis was used to determine an optimal formulation of PUbamboo-chips foam composites. The results showed that the acoustic properties of PU foam composites can be improved by optimizing the formulation of $\mathrm{PU}$ foams and the best combination values of variables were water of 4.6 , silicone oil of 1.8 , catalyst A1 of 0.08 and bamboo chips of 6 . By performing the confirmation test, the NRC had showed an increased value from 0.593 to 0.645 and the ATL showed an increased value from 15.35 to 16.75 , which had both positively improved the sound absorption and insulation properties.

\section{Acknowledgments}

This research is supported by National Natural Science Foundation project (No. 51575222), Jilin Provincial Natural Science Foundation project (20140101075JC), and China Postdoctoral Science Foundation Funded Project (2013T60322). The authors would like to express their appreciations for the above fund supports.

\section{References}

1. Adeli H., Zein S.H.S., Tan S.H., Ahmad A.L. (2011), Optimization of the mechanical strength properties of poly(l-lactide)/multi-walled carbon nanotube scaffolds using response surface methodology, Nano: Brief Reports and Reviews, 6, 2, 113-122.

2. ASTM International standard E-1050-98 (1998), Standard test method for impedance and absorption of acoustical materials using a tube, two micro-phones and a digital frequency analysis system, West Conshohocken, USA.

3. ASTM International standard E-2611-09 (2009), Standard test method for measurement of normal incidence sound transmission of acoustical materials based on the transfer matrix method, West Conshohocken, USA.

4. Andersson A., Lundmark S., Magnusson A, MaUER F.H.J. (2010), Vibration and acoustic damping of flexible polyurethane foams modified with a hyperbranched polymer, Journal of Cellular Plastic, 46, 1, 73-93.

5. Bahrambeygi H., Sabetzadeh N., Rabbi A., NaSOURI K., Shoushtari A.M. (2013), Nanofibers (PU and PAN) and nanoparticles (Nanoclay and MWNTs) simultaneous effects on polyurethane foam sound absorption, Journal of Polymer Research, 20, 2, 72-81.

6. Ekici B., Kentli A., Kucuk H. (2012), Improving sound absorption property of polyurethane foamsby adding tea-leaf fibers, Archives of Acoustics, 37, 4, 515520 .

7. Gayathri R., Vasanthakumari R. (2014), Nanomaterials in $P U$ foam for enhanced sound absorption at low frequency region, Advanced Materials Research, 938, 170-175.

8. Gayathri R., Vasanthakumari R., PadmanabHAN C. (2013), Sound absorption, thermal and mechanical behavior of polyurethane foam modified with nano silica, nano clay and crumb rubber fillers, International Journal of Scientific and Engineering Research, 4, 5, 301-308.

9. Gwon J.G., Kim S.K., Kim J.H. (2016), Sound $a b$ sorption behavior of flexible polyurethane foams with distinct cellular structures, Material and Design, 89, 448-454.

10. Huda S., Reddy N., YANG Y.Q. (2012), Ultra-lightweight composites from bamboo strips and polypropylene web with exceptional flexural properties, Composites: Part B, 43, 3, 1658-1664.

11. ISO International Standard 10534-2 (1998), Acousticdetermination of sound absorption coefficient and impedance in impedance tube: Part 2. Transferfunction method.

12. LeE J., Kim G.-H., HA C.-S. (2012), Sound absorption properties of polyurethane/nano-silica nanocomposite foams, Journal of Applied Polymer Science, 123 4, 2384-2390.

13. Li T.-T., Chuang Y.-C., Huang C.-H., Lou C.-W., LIN J.-H. (2015), Applying vermiculite and perlite fillers to sound-absorbing thermal-insulating resilient PU foam composites, Fibers and Polymers, 16, 3, 691698.

14. Low K.L., Tan S.H., Zein S.H.S., McPhail D.S., BocCaCCINI A.R. (2011), Optimization of the mechanical properties of calcium phosphatemulti-walled carbon nanotubesbovine serum albumin composites using res- 
ponse surface methodology, Materials and Design, 32, 6, 3312-3319.

15. Wang Y.H., Zhang C.C., Ren L.Q., IChChou M., Galland M.-A., Bareille O. (2013), Influences of rice hull in polyurethane foam on its sound absorption characteristics, Polymer Composites, 34, 11, 18471855 .

16. Welch W.J., BuCK R.J., SACKS J., Wynn H.P., Mitchell T.J., MorRis M.D. (1992), Screening, predicting, and computer experiments, Technometrics, 34, $1,15-25$.
17. Yin G.G., Oweimreen T., Ladewig J. (2011), Varying the polyurethane foam ratio for better acoustic performance and mass savings SAE Technical Paper 201101-1736, https://doi.org/10.4271/2011-01-1736.

18. Zhang C.H., Li J.Q., Hu Z., Zhu F., Huang Y. (2012), Correlation between the acoustic and porous cell morphology of polyurethane foam: Effect of interconnected porosity Materials and Design, 41, 319-325.

19. Zhou H., Li B., Huang G. (2006), Sound absorption characteristics of polymer microparticles Journal of Applied Polymer Science, 101, 4, 2675-2679. 